\title{
CARACTERIZAÇÃO DOS CASOS NOTIFICADOS DE ZIKA VÍRUS EM GESTANTES EM UM HOSPITAL DA REGIÃO CENTRO-OESTE
}

Nathalya da Silva Louro ${ }^{1}$

Amanda Santos Fernandes Coelho ${ }^{1}$

Marilia Cordeiro de Sousa ${ }^{2}$

Tainara Lucinda Junqueira ${ }^{1}$

Priscila Salomão da Silva ${ }^{3}$

Luiza Emylce Pelá Rosado https://orcid.org/0000-0001-5932-4630

https://orcid.org/0000-0001-5379-2740

https://orcid.org/0000-0001-6643-2365

https://orcid.org/0000-0002-8775-3448

https://orcid.org/0000-0001-9511-7444

https://orcid.org/0000-0002-5720-1984

Objetivo: Caracterizar o perfil das gestantes notificadas para Zika Vírus (ZIKV) em um hospital da região Centro-Oeste. Metodologia: Estudo transversal, descritivo, quantitativo e retrospectivo, composto por 311 casos suspeitos de ZIKV em gestantes atendidas em um Hospital Público de referência no período dezembro de 2015 a dezembro de 2017 . Análise com teste de qui-quadrado e Exato de Fisher. Resultados: Foram confirmados 180 (58\%) casos, predominou mulheres com idade entre 19-35 anos 250 (80\%), residentes em Goiânia 126 (70\%). Houve associação estatisticamente significante em relação aos casos confirmados em gestantes na faixa etária de 19 a 35 anos ( $p<0.0071)$, ocorrência de casos durante o segundo semestre de 2015 ( $p<0.0028$ ), e o primeiro semestre de 2016 ( $p<0.0000001$ ). Conclusão: Mediante o agravo que a infecção pelo ZIKV pode ocasionar durante a gestação, é imprescindível que os casos suspeitos sejam monitorados.

Descritores: Zika Virus; Gestante; Notificação Compulsória de Doença.

\section{CHARACTERIZATION OF THE REPORTED CASES OF ZIKA VIRUS IN PREGNANT WOMEN IN A HOSPITAL IN THE MIDWEST BRAZIL REGION}

Objective: To characterize the profile of pregnant women reported for Zika Virus (ZIKV) in a hospital in the Midwest. Methodology: A cross-sectional, descriptive, quantitative and retrospective study of 311 suspected ZIKV cases in pregnant women attending a Reference Public Hospital during the period of December 2015 to December 2017. Analysis using chi-square test and Fisher's exact test. Results: 180 (58\%) cases were confirmed, predominantly women aged between 19-35 years 250 (80\%), living in Goiânia 126 (70\%). There was a statistically significant association with confirmed cases in pregnant women aged 19-35 years $(p<0.0071)$, occurrence of cases during the second half of 2015 ( $p<0.0028)$, and the first half of 2016 ( $p<0.0000001)$. Conclusion: Due to the complications that infection by ZIKV can cause during pregnancy, it is necessary that the suspected cases are monitored.

Descriptors: Zika Virus, Pregnant Woman, Compulsory Disease Notification.

\section{CARACTERIZACIÓN DE LOS CASOS NOTIFICADOS DE ZIKA VIRUS EN EMBARAZADAS EN UN HOSPITAL DE LA REGIÓN CENTRO-OESTE}

Objetivo: Caracterizar el perfil de las mujeres embarazadas notificadas para Zika Virus (ZIKV) en un hospital de la región CentroOeste. Metodología: Estudio transversal, descriptivo, cuantitativo y retrospectivo, compuesto por 311 casos sospechosos de ZIKV en mujeres embarazadas atendidas en un Hospital Público de referencia en el período de diciembre de 2015 a diciembre de 2017. Análisis con prueba de chi-cuadrado y Exacto de Fisher. Resultados: Se confirmaron 180 (58\%) casos, predominó mujeres con edad entre 19-35 años 250 (80\%), residentes en Goiânia 126 (70\%). Se observó asociación estadísticamente significativa en relación a los casos confirmados en mujeres embarazadas en el grupo de edad de 19 a 35 años ( $p<0.0071)$, ocurrencia de casos durante el segundo semestre de 2015 ( $p<0.0028$ ), y el primer semestre de 2016 ( $p<0.0000001$ ). Conclusión: Mediante las complicaciones que la infección por el ZIKV puede ocasionar durante la gestación, es imprescindible que los casos sospechosos sean monitoreados.

Descriptores: Zika Virus, Embarazada, Notificación Obligatoria de Enfermedad. 


\section{INTRODUÇÃO}

O Zika Virus (ZIKV) é um ácido ribonucléico (RNA) da família Flaviviridae, transmitido pelo mosquito do gênero Aedes aegypti, o mesmo vetor responsável pela transmissão de Dengue e Chikungunya. Foi constatado a princípio em sangue de macacos, no ano de 1947, em Uganda na África ${ }^{(1)}$. O primeiro surto ocorreu em 2007 na Itha de Yap, na Micronésia, e posteriormente foram relatados surtos na Polinésia Francesa, espalhando-se para outras ilhas do Pacífico. No continente americano, a circulação do ZIKV foi identificada em 2014 (2).

Aproximadamente $80 \%$ dos individuos infectados apresentam-se assintomáticos, entretanto, quando sintomáticos, manifestam febre baixa, erupção pruriginosa, edema das extremidades, cefaleia e mialgia(2). Ainda que seja uma enfermidade de evolução benigna, na Polinésia Francesa, houve relatos de complicações neurológicas, como a Síndrome de Guillain-Barré( ${ }^{(3)}$.

No Brasil, o Ministério da Saúde (MS) confirmou a transmissão autóctone do ZIKV primeiramente na região Nordeste, em maio de $2015^{(4)}$. O vírus disseminou-se para as outras regiões do país e, no segundo semestre de 2015 , observou-se o aumento substancial das notificações de recém-nascidos (RN) com microcefalia no Sistema de Informação de Nascidos Vivos (SINASC) em alguns estados do Nordeste do Brasil, em especial, Paraíba, Pernambuco e Ceará, além dos registros de abortos espontâneos e natimortos ${ }^{(5)}$

Após descartar outras possíveis causas, os dados epidemiológicos sugeriam um nexo temporal entre o aumento das notificações de casos de microcefalia e o surto de ZIKV. A epidemia do ZIKV gerou um importante problema de saúde pública, a tal ponto que o Ministério da Saúde, em novembro de 2015, declarou emergência sanitária de importância nacional através da Portaria no 1.813 de 11 de novembro de $2015^{(6)}$.

Diante da rápida propagação do ZIKV e as anormalidades observadas, a Organização Mundial de Saúde (OMS), em 2016, lançou um alerta de emergência global sobre a relação entre a infecção em gestantes e o desenvolvimento de microcefalia em fetos ${ }^{(7)}$. O Brasil foi o primeiro país a identificar a relação entre a infecção pelo ZIKV na gestação e a ocorrência de microcefalia em $\mathrm{RN}^{(8)}$.

A infecção pelo ZIKV tornou-se doença de notificação compulsória após publicação da Portaria nㅇ 204, de 17 de fevereiro de 2016, considerando como caso suspeito paciente que apresentasse exantema acompanhado de dois ou mais dos seguintes sinais e sintomas: febre ou hiperemia conjuntival sem secreção e prurido ou poliartralgia ou edema periarticular(9)

O ano de 2016 foi considerado o ano epidêmico da doença no Brasil, logo, com o maior número de notificações desde 2015(10). Conforme o Boletim Epidemiológico n 37, no período de janeiro a agosto de 2016, dos 196.976 casos prováveis registrados de febre pelo ZIKV na população geral no pais, $(67,3 \%)$ foram em mulheres, dos quais $(72,8 \%)$ corresponderam a mulheres em idade fértil (faixa etária de 10 a 49 anos). As regiões Centro-Oeste e Nordeste apresentam as maiores taxas de incidência da doença na população no ano epidêmico(11).

Diante desse cenário, considerando que as gestantes compõemogrupo maisvulnerávelemrazão das consequências ocasionadas por infecção pelo ZIKV, o presente estudo tem o objetivo de caracterizar os casos das gestantes notificadas para o vírus ZIKV, em um hospital público de referência da região centro-oeste. Deste modo, a partir do conhecimento do perfil, será possível subsidiar ações para o desenvolvimento e aprimoramento de políticas públicas de saúde direcionadas para este público, principalmente no estado de Goiás.

\section{METODOLOGIA}

\section{Tipo de estudo}

Trata-se de um estudo transversal, descritivo, quantitativo e retrospectivo. Os dados foram obtidos a partir das fichas de investigação epidemiológica de casos de ZIKV notificados ao SINAN (Sistema de Informação de Agravos de Notificação), arquivadas no núcleo de Vigilância Epidemiológica do hospital de estudo

\section{Local do estudo}

Realizado em uma unidade de saúde estadual, com atendimento de média e alta complexidade, referência na área materno-infantil, inserido no contexto do Sistema Único de Saúde e que faz parte do fluxo de atendimento dos casos suspeitos de infecção por ZIKV em gestantes.

\section{Participantes da pesquisa}

A amostra da pesquisa foi composta por todas as notificações de casos de ZIKV em gestantes realizadas em um período de dois anos, a partir de dezembro de 2015 , quando tiveram início as notificações na unidade, até dezembro de 2017. Das 326 fichas preenchidas na instituição de saúde, 15 fichas não atenderam aos critérios de inclusão, consequentemente, não foram utilizadas no estudo. Portanto, foram analisadas 311 fichas de gestantes notificadas pelos profissionais de saúde.

Os critérios de inclusão foram todas as fichas de gestantes investigadas, e cujas conclusões dos casos tenham sido informadas (se descartadas ou confirmadas). Considerou-se 
como critério de exclusão o não preenchimento da data de notificação da ficha e da conclusão do caso.

\section{Coleta dos dados}

A coleta de dados foi realizada nos meses de maio a julho de 2018. Foram coletadas informações referentes à data da notificação, unidade de saúde notificadora, município da notificação, data dos primeiros sintomas, sintomas, classificação final da notificação, evolução do caso, variáveis sócio-demográficas (faixa etária, raça/cor, escolaridade, município, distrito e zona de residência) e trimestre gestacional. Essas informações foram registradas em planilha eletrônica no programa Microsoft Office Excel® 2017.

\section{Procedimentos de análise dos dados}

As informações foram analisadas através do programa eletrônico SPSS versão 3.5. Os dados quantitativos foram analisados descritivamente através de distribuição de frequências, médias e desvio padrão. Testes de significância adequados ao tamanho da amostra foram aplicados para verificar as diferenças estatísticas entre as proporções, isto é, estas proporções foram comparadas pelo teste do 2 . acompanhado do teste exato de Fisher ou teste de correção de Yates. Foram consideradas estatisticamente significantes as diferenças em que $p$ foi menor que $5 \%(p<0,05)$.

\section{Procedimentos éticos}

O estudo foi aprovado pelo Comitê de Ética em Pesquisa via Plataforma Brasil, obtendo parecer consubstanciado 2.616.930 e CAAE: 80907417.6.0000.5080 e desenvolvido segundo os princípios éticos estabelecidos pela Resolução do Conselho Nacional de Saúde no 466/2012

\section{RESULTADOS}

Em relação à caracterização sociodemográfica das gestantes notificadas, o presente estudo verificou que a faixa etária que predominou foi de 19 a 35 anos (80\%) e com média de idade de $26,5 \pm 6,3$ anos, a maioria de raça não branca (63\%), com mais de oito anos de tempo de estudo (90\%), residente na Capital (70\%) e zona urbana $(99,68)$.

Os casos notificados em gestantes que residem na capital de Goiás, segundo os distritos sanitários, apresentam a seguinte distribuição: leste $5 \%$, norte $6 \%$, sul $6 \%$, noroeste $14 \%$, sudoeste $18 \%$, campinas Centro $19 \%$, e oeste $21 \%$.

Quanto aos dados da notificação compulsória, houve predomínio de casos confirmados, 180 casos (58\%), com maior ocorrência de notificações no primeiro semestre de 2016 (71\%), com gestação no segundo trimestre no momento da notificação (34\%) e os principais profissionais de saúde notificadores foram Enfermeiros (99\%), dados descritos na (Tabela l)

Tabela 1. Distribuição dos casos notificados de gestantes com suspeita de infecção pelo ZIKV, segundo os dados da notificação em um Hospital Estadual, entre 2015 a 2017. Goiânia, Goiás, 2019.

\begin{tabular}{|c|c|}
\hline Dados da notificação & $n(\%)$ \\
\hline \multicolumn{2}{|l|}{ Classificação final } \\
\hline Confirmado & $180(58)$ \\
\hline Descartado & $131(42)$ \\
\hline \multicolumn{2}{|c|}{ Notificações por semestre/ano } \\
\hline \multicolumn{2}{|l|}{10 semestre } \\
\hline 2016 & $222(71)$ \\
\hline 2017 & $45(15)$ \\
\hline \multicolumn{2}{|l|}{20 semestre } \\
\hline 2015 & $6(2)$ \\
\hline 2016 & $15(5)$ \\
\hline 2017 & $23(7)$ \\
\hline \multicolumn{2}{|c|}{ Trimestre de gestação/Momento da notificação } \\
\hline 1 trimestre & 103(33) \\
\hline 20 trimestre & 105(34) \\
\hline 3 으 trimestre & 103(33) \\
\hline \multicolumn{2}{|l|}{ Viagem recente } \\
\hline Sim & $5(1)$ \\
\hline Não & $30(10)$ \\
\hline Não Informado & $276(89)$ \\
\hline \multicolumn{2}{|c|}{ Profissional de saúde notificador } \\
\hline Enfermeiro & 308(99) \\
\hline Outros profissionais & $3(1)$ \\
\hline
\end{tabular}

Fonte: dados da pesquisa.n: número de casos. \%: porcentagem.

Ao analisar os casos notificados por suspeita de infecção pelo ZIKV, em gestantes na unidade de estudo, utilizando as variáveis sociodemográficas e os dados da notificação, constatou-se associação estatisticamente significante em relação aos casos confirmados e a faixa etária das gestantes de 19 a 35 anos de idade $(p<0,0071)$, notificações realizadas no $2^{\circ}$ semestre de 2015 ( $\left.p<0,0000001\right)$ e $1^{\circ}$ semestre de 2016 ( $p<0,0028$ ) , como mostra a (Tabela 2). Na apresentação dos resultados das variáveis raça e escolaridade, foram desprezados os dados sem informação. O que altera o percentual final. 
Tabela 2. Associação entre as variáveis sociodemográficas e os dados da notificação de ZIKV em um Hospital Estadual, entre 2015 a 2017. Goiânia, Goiás, 2019.

\begin{tabular}{|c|c|c|c|}
\hline \multirow{2}{*}{ Variáveis } & \multicolumn{2}{|c|}{ Conclusão dos casos } & \\
\hline & Confirmados & Descartados & \\
\hline & $n(\%)$ & $\mathrm{n}(\%)$ & Valor $p$ \\
\hline \multicolumn{4}{|c|}{ Municipio } \\
\hline Goiânia & $126(70)$ & $93(30)$ & $0.9494^{*}$ \\
\hline $\begin{array}{l}\text { Outros } \\
\text { municipios }\end{array}$ & $54(71)$ & 38(29) & \\
\hline \multicolumn{4}{|c|}{ Raça } \\
\hline Raça branca & $50(55)$ & $41(45)$ & $0.5093^{*}$ \\
\hline Raça não branca & $92(71)$ & $61(29)$ & \\
\hline \multicolumn{4}{|c|}{ Escolaridade } \\
\hline$<8$ anos & $13(62)$ & $8(38)$ & $0.7070^{*}$ \\
\hline$\geq 8$ anos & 100(55) & $82(45)$ & \\
\hline \multicolumn{4}{|c|}{ Faixa etária } \\
\hline$\leq 18$ anos & $21(64)$ & $12(36)$ & $0.6015^{*}$ \\
\hline 19 a 35 anos & $150(60)$ & $100(40)$ & $0.0071^{*}$ \\
\hline$\geq 36$ anos & 9(32) & $19(68)$ & $0.1647^{*}$ \\
\hline \multicolumn{4}{|c|}{ Trimestre de gestação no momento da notificação } \\
\hline $1^{\circ}$ Trimestre & 6l(59) & $42(41)$ & $0.8289^{*}$ \\
\hline $2^{\circ}$ Trimestre & $56(53)$ & $49(47)$ & $0.4813^{*}$ \\
\hline $3^{\circ}$ Trimestre & $63(61)$ & 40(39) & $0.3013^{*}$ \\
\hline \multicolumn{4}{|c|}{ Zona } \\
\hline Zona urbana & $180(58)$ & 130(42) & $0.8730^{*}$ \\
\hline Zona Rural & - & $1(100)$ & \\
\hline \multicolumn{4}{|c|}{ 10 Semestre } \\
\hline 2016 & $164(74)$ & $58(26)$ & $0.0000001^{* *}$ \\
\hline 2017 & $12(27)$ & $33(73)$ & \\
\hline \multicolumn{4}{|c|}{ 2ㅇ Semestre } \\
\hline 2015 & $3(50)$ & $3(50)$ & $0.0028^{* *}$ \\
\hline 2016 & $1(7)$ & $14(93)$ & $0.8801^{* *}$ \\
\hline 2017 & - & 23(100) & $0.2684^{\star *}$ \\
\hline
\end{tabular}

Fonte: Dados da pesquisa.n: número de casos *Teste de quiquadrado corrigido de Yates; ${ }^{* \star}$ Exato de Fisher.

Em relação aos sinais e sintomas apresentados pelas gestantes notificadas, independentemente da conclusão do caso, os mais frequentes foram: exantema (81\%), prurido (41\%), cefaleia (20\%), febre (20\%), mialgia (19\%), artralgia (14\%) e dor retro-ocular (14\%). Entre os casos confirmados por critério laboratorial para infecção por ZIKV, os sintomas mais frequentes foram: exantema (86\%) e prurido (44\%).

\section{DISCUSSÃo}

A detecção da infecção por ZIKV em gestantes tornouse prioritária em todo território nacional após a associação da infecção materna durante a gestação com microcefalia no feto. A região Centro-Oeste, no ano de 2016, apresentou as maiores taxas de incidência da doença na população. Em 2017 manteve-se com os elevados números de coeficiente de incidência entre as demais regiões do país ${ }^{(10)}$.

Nesse estudo, o primeiro semestre de 2016 foi o período que apresentou a maior ocorrência de casos suspeitos notificados (71\%), sendo mais frequentes nos meses de fevereiro (33\%) e março (28\%), corroborando com Informe Epidemiológico $n^{\circ} 47$ do Ministério da Saúde, o qual evidenciou uma maior concentração de casos entre as semanas epidemiológicas 7 e 9, correspondentes respectivamente aos meses de fevereiro e março de $2016^{(12)}$. No tocante à distribuição temporal dos casos durante a epidemia, a curva de ZIKV assemelha-se à curva de dengue, com transmissão importante no período compreendido entre as semanas epidemiológicas 3 (janeiro) a 15 (abril) de $2016^{(11)}$.

Verificou-se no presente estudo que a maioria das gestantes reside na capital (70\%). A cidade de Goiânia é composta por sete Distritos Sanitários (DS), que são definidos a partir de critérios epidemiológicos e sociais semelhantes, verificando-se uma distribuição diferente entre os DS. É importante manter a vigilância entomológica do Aedes em criadouros tanto artificiais como naturais, principalmente em áreas urbanas, com o propósito de serem contidos surtos de Dengue, Zika e Chikungunya ${ }^{(12)}$.

Somente $10 \%$ da população goiana reside em área rural e nessa amostra evidenciou-se apenas um caso notificado. No presente estudo, a maioria das gestantes reside em zona urbana. A habituação do ZIKV a um ciclo urbano e regiões próximas, através do Aedes aegypti e outros mosquitos do subgênero como vetores, tendo o humano como principal hospedeiro, deve ser uma grande preocupação para as autoridades de saúde pública(1)

As arboviroses são consideradas problemas de saúde pública, essencialmente pelo seu potencial de disseminação e contágio, pela facilidade de adaptação a novos cenários e a gravidade de alguns casos com acometimentos neurológicos e, portanto, a circulação vetorial não deve ser negligenciada ${ }^{(13)}$.

$\mathrm{Na}$ presente pesquisa, as mulheres jovens em idade reprodutiva foram as mais acometidas pela infecção (60\%). Tal fato corrobora o estudo nacional realizado a partir dos dados do SINAN,nos quais predominou a faixa etária de 20 a 39 anos de idade, correspondendo a (44,7\%) dos casos de ZIKV em mulheres ${ }^{(11)}$. $O$ dado relativo à faixa etária de 19 a 35 anos foi estatisticamente significante nessa pesquisa quando associado aos casos confirmados. Segundo a OMS, considera-se que o período reprodutivo em mulheres está compreendido entre a idade de 15 a 49 anos $^{(14)}$.

$O$ estudo de Coelho et al $^{(15)}$ evidenciou que mulheres em faixa etária sexualmente ativa apresentam maior predisposição à infecção por ZIKV do que os homens, com 
aumento de $90 \%$, e que tal fato provavelmente se relacione com a transmissão sexual. Além disso, a identificação do vírus em mulheres é maior, o que pode estar relacionado à maior frequência das mulheres em consultas médicas e, deste modo, o vírus é detectado se estiverem infectadas.

Houve predomínio nesse estudo de gestantes com escolaridade cujo tempo de estudo foi maior que oito anos (63\%). A escolaridade materna reflete as condições socioeconômicas e se associa a um maior risco de morte neonatal, portanto é um fator de risco que contribui na questão da sobrevivência infantil e em indicadores de condição socioeconômica ${ }^{(17)}$. No estudo de Santana et al ${ }^{(17)}$, constatou-se que as mulheres negras apresentam histórico frequente de adoecimento por arbovirose, e que o ambiente onde elas vivem influencia na condição de adoecimento.

Nesse trabalho, houve predomínio dos casos notificados no segundo trimestre gestacional, e, desses, a maioria foi positiva para ZIKV (53\%). Tal resultado é semelhante ao encontrado no estudo de Nogueira et $\mathrm{al}^{(18)}$, em que, dos 54 casos positivos para ZIKV, 48\% foram durante o segundo trimestre, tendo ainda concluído que a infecção deve ser considerada importante em qualquer trimestre gestacional. Entretanto, de acordo com outros estudos, a infecção materna no primeiro trimestre é considerada de maior risco de transmissão ao feto(19,20,21)

Em relação à conclusão dos casos do presente estudo, a maioria foi confirmada (58\%). Estudo de coorte realizado no Rio de Janeiro, no período de setembro de 2015 a maio de 2016, acompanhou prospectivamente 345 grávidas, e buscou obter dados da gestação e os desfechos neonatais, destas, 53\% obtiveram resultados positivos para ZIKV(22). Estudo realizado no sistema público de saúde de São José do Rio Preto, entre fevereiro e outubro de 2016, acompanhou 216 gestantes com suspeita de ZIKV, destas, $26 \%$ obtiveram resultado positivo para infecção pelo ZIKV e 74\% obtiveram resultado descartado(18).

Neste trabalho, no que diz respeito aos profissionais que realizaram as notificações, houve destaque para o profissional Enfermeiro. O enfermeiro destaca-se na assistência a gestante especialmente na atenção ao pré-natal, pois assume papel cada vez mais decisivo e proativo ofertando informações e disponibilizando cuidados para que a gestação ocorra sem riscos à saúde da mãe e do concepto(23).

Em relação ao preenchimento da notificação compulsória de acordo com Portaria n 104 de 25 de janeiro de 2011, “a notificação é obrigatória a todos os profissionais de saúde, bem como os responsáveis por organizações e estabelecimentos públicos e particulares de saúde e de ensino"(24).

A notificação de doença favorece meios para vigiar a saúde da população. Porém, a falta de conhecimento por parte dos profissionais em relação às ações da vigilância epidemiológica pode contribuir com a não realização da notificação, prejudicando assim o funcionamento do sistema de notificação vigente no país. O conhecimento sobre a doença e da forma de notificação aos órgãos responsáveis é primordial para prevenção e controle de epidemias(25).

\section{Limitações do estudo}

Este estudo apresentou algumas limitações por ter metodologia do tipo transversal e descritivo, com dados utilizados a partir da ficha de notificação, haja vista que algumas informações podem ser registradas de forma incompleta ou inadequada, deste modo algumas informações podem ser perdidas; além disso, o conhecimento a respeito do seguimento e desfechos das gestações e também a realização do estudo em apenas uma unidade de saúde, assim são necessários outros estudos semelhantes em outras regiões no âmbito nacional e mundial.

\section{Contribuições do estudo para a prática}

Tendo em vista as várias lacunas ainda existentes no conhecimento sobre a infecção pelo vírus Zika, o presente estudo, a partir da caracterização dos casos notificados de Zika em gestantes, contribui para fortalecer o conhecimento de enfermeiros e profissionais de saúde que atuam no atendimento a mulheres em idade fértil, principalmente durante o período gestacional, subsidiando a formulação de protocolos assistenciais, atenção as ações de vigilância epidemiológica, planejamento familiar, cuidados no pré-natal, atenção ao parto e ao nascimento e orientações de medidas de prevenção contra arboviroses.

\section{CONCLUSÃO}

A infecção por ZIKV deve ser devidamente notificada em casos suspeitos. É necessária a capacitação dos profissionais de saúde sobre as ações da vigilância em saúde, visto que a notificação é uma ferramenta importante para vigilância de novos casos e a identificação de surtos e epidemias.

O incentivo a ações de controle vetorial é indispensável no combate às arboviroses, além do acompanhamento prénatal às gestantes, pois essas devem receber orientações quanto a medidas de proteção individual contra a infecção por ZIKV, como o uso de repelentes, de roupas apropriadas que as protejam contra a picada de mosquitos em áreas de circulação viral e de preservativos quando o contato sexual apresentar quadro suspeito de infecção por ZIKV.

São necessários também novos estudos que associem fatores de risco maternos com desfecho ao RN no contexto dessa infecção e que direcionem a implantação de políticas públicas que contribuam com melhores resultados nos 
indicadores de morbidade materna e neonatal.

Declaramos que não houve conflitos de interesse. O financiamento do estudo foi integralmente de responsabilidade dos próprios pesquisadores.

Agradecemos à instituição da pesquisa e ao Programa de Residência Uniprofissional de Enfermagem Obstetrícia da Secretaria de Estado da Saúde de Goiás.

\section{Contribuição dos autores}

Concepção e desenho, Análise e interpretação dos dados, Redação do artigo, Revisão crítica, Revisão final: Nathalya da Silva Louro, Amanda Santos Fernandes Coelho, Marília Cordeiro de Sousa, Tainara Lucinda Junqueira, Priscila Salomão Silva, Luiza Emylce Pelá Rosado.

\section{REFERÊNCIAS}

1. Musso D, Lormeau VMC, Gubler DJ. Zika virus: following the path of dengue and Chikungunya?. The Lancet [Internet].2015[cited 2017 nov 11]: 386 (9990): 243-244 Available from: https://www.thelancet.com/journals/lancet/article/PIISO140-6736(15)61273-9/fulltext?code=lancet-site.

2. Lopes MH, Miyaji KT, Infante V. Zika Virus. Rev. Assoc. Med. Bras. [Internet].2016 [cited 2018 out 28];62(1): 4-9. Available from: http://www.scielo. br/scielo.php?pid=S010442302016000100004Escript=sci_arttext

3. LuzKG, Santos GIV, Vieira RM. FebrepelovírusZika. Epidemiol. Serv. Saúde. [Internet]. 2015[cited 2018 nov 15];24(4):785-788. Available from: https:// www.scielosp.org/scielo.php?pid=S2237-962220150004007858script=sci_arttext\&tln

4. Ministério da Saúde (Brasil). Secretaria de Vigilância em Saúde. Virus Zika no Brasil: a resposta do SUS [recurso eletrônico]. $1^{\circ}$ edição. BrasiliaMinistério da Saúde, 2017. [cited 2017 out 23] Available from: <http://bvsms.saude.gov.br/bvs/publicacoes/virus_zika_brasil_resposta_sus.pdf>

5. Sáfadi, MAP. Zika Virus: What Have We Leanerd?. Amer. J Perinatol. [Internet]. 2018 [cited 2018 nov 12]:33(11):1029-1031. Available from: https: 10.1055 / s-0036-1586116

6. Brasil. Ministério da Saúde. Portaria no 1.813 de 11 de novembro de 2015 . Declara Emergência em Saúde Pública de importância Nacional (ESPIN) por alteração do padrão de ocorrência de microcefalias no Brasil Internet]. Diário Oficial da República Federativa do Brasil. 2015 nov 11 . [cited 2018 out 03]. Available from: http://bvsms.saude.gov.br/bvs/saudelegis/ gm/2015/prt1813_11_11_2015.html

7. Organização Mundial da Saúde(OMS). Declaração da OMS sobre a primeira reunião do Regulamento Sanitário Internacional:Comitê de Emergência sobre o Zika virus e aumento observado em distúrbios neurológicos e malformações neonatais [Internet]. 2016 [cited 2018 out 03]. Available from: http://www.who.int/mediacentre/news/statements 2016 / 1--comitê de emergência-zika /

8. Oliveira, CS, Vasconcelos, PFC. Microcefalia e virus Zika. J. Pediatr. (Rio J.).[Internet]. 2016 [cited 2018 out 13]; 92(2):103-105. Available from: : http://www.scielo.br/scielo.php?script=sci_arttext\&pi$\mathrm{d}=$ S0021-755720160002001038lng=en\&nrm=iso

9. BRASIL. Ministério da Saúde. Portaria no 204 de 17 de fevereiro de 2016 Define a Lista Nacional de Notificação Compulsória de doenças, agravos e eventos de saúde pública nos serviços de saúde públicos e privados em todo o território nacional, nos termos do anexo, e dá outras providências. Diário Oficial da República Federativa do Brasil. 2016 fev 18; Seção 1:23. [cited 2017 set 24]. Available from: : http://bvsms.saude.gov.br/bvs/saudelegis/gm/2016/prt0204_17_02_2016.html

10. Brasil. Ministério da Saúde, Boletim Epidemiológico Situação epidemiológica da infecção pelo virus Zika no Brasil, de 2015 a 2017. Secretaria de Vigilância em Saúde. v.49, n.47, p.1-10, 2018, [cited 2017 out O1]. Available from: <http://portalarquivos2.saude.gov.br/images/pdf/2016/novembro/15/2016_031Mulheres_publicacao.pdf>

11. Ministério da Saúde (Brasil). Secretaria de Vigilância em Saúde. Boletim Epidemiológico Zika Virus: Perfil Epidemiológico em mulheres [Internet]. 2016 [cited 2018 out 02]; 47(37): 1-7. Available from: http:// portalarquivos2. saude.gov.br/images/pdf/2016/novembro/15/2016_031-Mulheres_publicacao.pdf

12. Lima-camar TN, Urbinatti PR, Chiaravalloti FN. Encontro de Aedes aegypti em criadouro natural de área urbana. Rev. de Saúde Pública [Internet]. 2016 [cited 2018 nov 11]; 50(3): 1-4. Available from: <http://www. redalyc.org/pdf/672/67247719057.pdf>

13. Donalisio MR, Freitas ARR, Von Zuben APB. Arboviroses emergentes no Brasil: desafios para a clínica e implicações para a saúde pública. Rev. de Saúde Pública [Internet]. 2017 [cited 2019 jan 03]; 51(30): 1-6. Available from: http://dx.doi.org/10.1590/s1518-8787.2017051006889

14. rganização Mundial da Saúde (OMS). Mulheres e saúde: evidências de hoje, agenda de amanhã. 2009. [cited 2018 nov 10]. Available from: http:// www.who.int/ageing/mulheres_saude.pdf.
15. Coelho FC, Durovni B Saraceni V Lemos C Codeco CT, Camargo S. et al. A maior incidência de zika em mulheres adultas do que em homens adultos no Rio de Janeiro sugere uma contribuição significativa da transmissão sexual de homens para mulheres. International Journal of Infectious Diseases [Internet]. 2016[cited 2018 out 11] 51:128-132. Available from:https://doi.org/10.1016/j.jid.2016.08.023

16. Gonçalves AE, Tenório SDB, Ferraz PCS. Aspectos socioeconômicos dos genitores de criancas com microcefalia relacionada ao Zika Virus. RevPesqFisio.[Internet]. 2018 [cited 2018 set 29]:8(2):155-166. Available from: https://doi: 10.17267/2238-2704rpf.v8i2.1865.

17. Santana KSO, Guimarães ICS, Junior AD'O. Assistência à saúde de gestantes negras e não negras em epidemia de zika virus no municipio de Salvador, Ba. Convención Internacional de Salud, Cuba Salud.Internet] Abril 2018. [cited 2018 dez 04]; Havana-Cuba Available from: www. convencionsalud2017.sld.cu/index.php/connvencionsalud/2018/paper/ viewPaper/1164

18. Nogueira ML, Nery Junior NRR, Estofolete CF, Terzian ACB, Guimarães GF, Zini N. et al. Desfechos adversos do nascimento associados à exposição ao zika virus durante a gravidez em São José do Rio Preto,Brasil. Clinical Microbiology and Infection [Internet]. 2018 [cited 2018 out 28]; 24 (6):646-652. Available from: https://doi.org/10.1016/j.cmi.2017.11.004

19. Cauchemez S, Besnad M, Bompard P, Dub T, Guillemette-Artur, Eyrolle-Guinot, et al., Associação entre o virus Zika e a microcefalia na Polinésia Francesa, 2013-2015: um estudo retrospectivo. Lancet [Internet]. 2016 [cited 2018 nov 11];387(10033): 2125-2136. Available from: <https://www. ncbi.nlm.nih.gov/pmc/articles/PMC4909533/>

20. Cunha DP, Alterações morfológicas e detecção viral em placentas de gestantes infectadas com o virus zika. [Dissertação de mestrado]:Rio de Janeiro: Fundação Oswaldo Cruz, Instituto Nacional de Saúde da Mulher da criança e do adolescente Fernandes Figueira. 2017. Available from: www.arca.fiocruz.br/handle/icict/27412

21. Honein MA, Dawson AL, Peterson EE, Jones AM, Lee EH. Yazdy MM, et al. Defeitos congênitos entre fetos e bebês de mulheres americanas com evidência de possivel infecção pelo zika virus durante a gravidez. JAMA [Internet]. 2017 [cited 2018 out 28]: 317 (1): 59-68. Available from: https:// jhttps://jamanetwork.com/journals/jama/article-abstract/2671017?resultClick=1. Doi: 10.1001 / jama.2016.19006

22. Brasil P, Junior Pereira JP, Moreira ME, Nogueira RMR, Damasceno L. Wakimoto M, et al. Infecção por virus Zika em mulheres grávidas no Rio de Janeiro. N Engl J Med [Internet]. 2016 [cited 2018 out 28]; 375(24): 2321-2334. Available from: <https://www.ncbi.nlm.nih.gov/pmc/articles/ PMC5323261/>

23. Primo CC, Trevizani CC, Tedesco JC, Costa Leite FMC, Almeida MVS, Lima EFA. Classificação internacional para a prática de enfermagem na assistência pré-natal. Enferm Foco [Internet]. 2015 [cited 2019 Mar 21] 6 (1/4):17-23. Available from: http://revista.cofen.gov.br/index.php/enfermagem/article/view/571/253

24. Brasil. Ministério da Saúde. Portaria no 104 de 25 de JANEIRO de 2011: as terminologias adotadas em legislação nacional, conforme o disposto no Regulamento Sanitário Internacional 2005 (RSI 2005), a relação de doenças, agravos e eventos em saúde pública de notificação compulsória em todo o território nacional e estabelece fluxo, critérios, responsabilidades e atribuições aos profissionais e serviços de saúde. Diário Oficial da República Federativa do Brasil. 2011 jan 25. [cited 2017 nov 24]. Available from: http://bvsms.saude.gov.br/bvs/saudelegis/gm/201l/ prt0104_25_01_2011.htm.

25. Silva, GA; Oliveira, CML. O registro das doenças de notificação compulsória: a participação dos profissionais da saúde e da comunidade. Revista de Epidemiologia e Controle de Infecção [Intenert]. 2014 [cited 2019 jan 17]4(3):215-220, 2014. Available from:http://online.unisc.br/seer/index. php/epidemiologia/article/view/4578 